\title{
Azaarenes in fine particulate matter from the atmosphere of a Chinese megacity
}

\author{
Benjamin A. Musa Bandowe ${ }^{1,2}$ - Hannah Meusel ${ }^{3}$ - Rujin Huang 4,5,6,7 \\ Thorsten Hoffmann ${ }^{7}$ • Junji Cao ${ }^{4}$ Kinfai $\mathrm{Ho}^{8}$
}

Received: 16 February 2016/Accepted: 22 April 2016/Published online: 4 May 2016

(C) Springer-Verlag Berlin Heidelberg 2016

\begin{abstract}
Azaarenes (AZAs) are toxicologically relevant organic compounds with physicochemical properties that are significantly different from the well-studied polycyclic aromatic hydrocarbons (PAHs). However, little is known about their concentrations, seasonal variations, fate, and relationship with PAHs in air. This paper reports the temporal variations in the concentrations and composition patterns of AZAs in $\mathrm{PM}_{2.5}$ that was
\end{abstract}

Responsible editor: Constantini Samara

Electronic supplementary material The online version of this article (doi:10.1007/s11356-016-6740-z) contains supplementary material, which is available to authorized users.

Benjamin A. Musa Bandowe

benjamin.bandowe@giub.unibe.ch

1 Institute of Geography, University of Bern, Hallerstrasse 12, 3012 Bern, Switzerland

2 Oeschger Centre for Climate Change Research, University of Bern, Falkenplatz 16, 3012 Bern, Switzerland

3 Multiphase Chemistry Department, Max Planck Institute for Chemistry, Hahn-Meitner-Weg 1, 55128 Mainz, Germany

4 Key Laboratory of Aerosol Chemistry \& Physics, Institute of Earth Environment, Chinese Academy of Sciences, 10 Fenghui South Road, 710075 Xi'an, China

5 Centre for Atmospheric and Marine Sciences, Xiamen Huaxia University, Xiamen 361024, China

6 Laboratory of Atmospheric Chemistry, Paul Scherrer Institute, 5232 Villigen, Switzerland

7 Institute of Inorganic and Analytical Chemistry, Johannes Gutenberg University Mainz, Duesbergweg 10-14, 55128 Mainz, Germany

8 Jockey Club School of Public Health \& Primary Care, The Chinese University of Hong Kong, Sha Tin, Hong Kong sampled once per 6 days from outdoor air of Xi'an, China from July 2008 to August 2009. The concentrations of the $\sum A Z A s$, quinoline (QUI), benzo[h] quinoline (BQI), and acridine (ACR) in $\mathrm{PM}_{2.5}$ were 213-6441, 185-520, 69-2483, and 10-3544 $\mathrm{pg} \mathrm{m}^{-3}$, respectively. These concentrations were higher than those measured in urban areas of Western Europe. AZA compositional patterns were dominated by BQI and ACR. The high concentration of AZAs, high AZA/related $\mathrm{PAH}$ ratio, and the dominance of three-ring AZAs (BQI and $\mathrm{ACR}$ ) in $\mathrm{PM}_{2.5}$ of $\mathrm{Xi}$ 'an are all in contrast to observations from Western European and North American cities. This contrast likely reflects differences in coal type and the more intense use of coal in China. The $\mathrm{PM}_{2.5^{-}}$ bound concentration of AZA in winter season (W) was higher than during the summer season (S) with W/S ratios of 5.7, 1.4, 4.1, and 13, for $\sum A Z A s, Q U I, B Q I$, and ACR, respectively. Despite their significantly different physicochemical properties, AZAs were significantly $(p<0.05)$ positively correlated with their related PAHs and pyrogenic elemental carbon. The changes in AZA concentrations were positively correlated with ambient pressure but negatively correlated with ambient temperature, wind speed, and relative humidity. This trend is similar to that observed for the related PAHs. We conclude that Xi'an and possibly other Chinese cities have higher emission of AZAs into their atmosphere because of the more pronounced use of coal. We also conclude that in spite of differences in physicochemical properties between AZAs and related PAHs, the atmospheric dynamics and relationships with meteorological factors of both compound groups are similar.

Keywords Azaarenes $\cdot$ PAHs $\cdot \mathrm{PM}_{2.5} \cdot$ Chinese megacity Seasonal change $\cdot$ Meteorological conditions 


\section{Introduction}

Several published studies report a link between air particulate matter (PM) and the level of diseases borne by people living in or near cities and industrial zones (Pope and Dockery 2006; Cao et al. 2012). Higher levels of cardiovascular diseases, respiratory diseases, lung cancer, developmental and reproductive disorders, premature mortality and morbidity are all associated with inhalation of air contaminated with fine PM (Nel 2005; Millman et al. 2008; Cao et al. 2012). Economic growth, industrialization, and urbanization in China have all accelerated over the past few decades. These rapid transitions, which far outpace environmental protection measures, have resulted in severe cases of air pollution by PM and increased exposure of people to toxic air pollutants in many urban areas in China (Streets et al. 2006; Chan and Yao 2008; Huang et al. 2014). This situation has negative consequences for human health, general well-being (lower quality of life), and workplace productivity. These also result in high financial costs due to loss of working time and treatment of ailments (Zhang et al. 2009; Cao et al. 2012; Kan et al. 2012; Matus et al. 2012). The negative effects of exposure to fine PM are related to their small size, morphology, and high concentration of toxic chemicals bound to them (Harrison and Yin 2000). Polycyclic aromatic compounds (PACs) are prime suspects in the toxicity, mutagenicity, and estrogenicity of PM (Harrison and Yin 2000; Harrison et al. 2004; GerlofsNijland et al. 2009; Wei et al. 2009). Previous studies that characterized the composition of toxic chemicals in PM were focused on polycyclic aromatic hydrocarbons (PAHs) or only benzo[a]pyrene probably because these are covered by air quality regulations in China, European Union, North America, and several other countries (European Union 2005; Wang et al. 2006; Ravindra et al. 2008; Ministry of Environmental Protection of The People's Republic of China 2012). However, other PACs like nitrogen-heterocyclic polycyclic aromatic compounds (azaarenes or AZAs) also show toxic effects. The toxic, mutagenic, carcinogenic, and estrogenic effects of some AZAs are higher than for some PAHs (Machala et al. 2001; Jung et al. 2001; IARC 2011). Several AZAs have been classified as probable/possible human carcinogens and assigned toxicity equivalence factors which are higher than those of some PAHs (Collins et al. 1998; IARC 2011). $\mathrm{PM}_{2.5}$, their bound AZAs, PAHs, and pyrogenic/ elemental carbon (EC) are co-emitted into the atmosphere of urban environment from the combustion of fossil fuels (coal, oil) and biomass that take place during household heating, cooking, municipal waste incineration, transportation, industrial/power production, farming, and natural fires (Wilhelm et al. 2000; Bleeker et al. 2002; Boström et al. 2002; Bi et al. 2008; Junninen et al. 2009; Vicente et al. in press). Compared to PAHs with equal number of benzene rings (related PAHs), AZAs tend to have higher water solubility, lower octanol-water $\left(\mathrm{K}_{\mathrm{OW}}\right)$, lower octanol-air partition coefficients $\left(\mathrm{K}_{\mathrm{OA}}\right)$, and lower vapor pressures (Table 1, Figure S1).

AZAs also have unpaired electrons, acid/base characteristics, and can exist in protonated (ionic forms) form under the right $\mathrm{pH}$ conditions (Kochany and Maguire 1994; Chen and Preston 2004; Reineke et al. 2007). AZAs might be washed out of the atmosphere by precipitation (especially with low $\mathrm{pH}$ ) in more significant amounts than related PAHs because of their higher water solubility and acid/base properties (Osborne et al. 1997; Chen and Preston 2004). Furthermore, AZAs can be more strongly sorbed to charged surfaces of minerals and organic materials in atmospheric PM (by ionic and/or polar intermolecular forces) through their unpaired electrons and protonated ionic forms. Thus, the interactions of AZAs with sorbents in PM are different from those of their related PAHs whose sorption to PM is mainly by hydrophobic and weak van der Waal forces (Osborne et al. 1997; Chen and Preston 1997; Chen and Preston 2004; Bi et al. 2006; Arp et al. 2008). The above factor/properties could have enormous effects on the levels, temporal trends, gas/particle partitioning, particle size distribution, deposition patterns, and toxic effects of AZAs in air that are less predictable and different from their related but more hydrophobic PAHs (Chen and Preston 1997; Bandowe et al. 2014a). We therefore hypothesize that AZAs behave differently with respect to interaction with carbon fractions in atmospheric PM and meteorological conditions than related PAHs. However, up to now, not enough studies have been conducted on atmospheric AZAs with regards to their concentration levels, composition pattern, sources, fate, and behavior. The relationship of atmospheric AZAs with other co-emitted atmospheric pollutants (e.g., EC, PAHs) and meteorological conditions is sparsely investigated (Chen and Preston 1997; Lintelmann et al. 2010; Delhomme and Millet 2012). There are no studies on $\mathrm{PM}_{2.5}$-bound AZAs in China. However, the concentrations of AZAs in air of China could be very high because coal combustion (which is a significant source of AZAs) constitutes a large percentage of fuels currently used in China (Millman et al. 2008; Junninen et al. 2009; You and $\mathrm{Xu} 2010$ ).

We recently reported the levels, temporal trends, composition pattern, and sources of a range of PACs (PAHs, oxygenated PAHs (OPAHs), nitrated-PAHs) in $\mathrm{PM}_{2.5}$ (from Xi'an, China) sampled once per 6 days from July 2008 to August 2009. This previous study also evaluated the effects of seasonality and meteorological conditions on the levels, sources, composition pattern, and fate of the PACs groups listed above (Bandowe et al. 2014a). The current paper focuses on AZAs that was measured in the same samples as used in the previous paper with the following objectives: (1) to study the concentrations, temporal trends, and composition pattern of $\mathrm{PM}_{2.5^{-}}$ bound AZAs in the atmosphere of the Chinese megacity of Xi' an, (2) to compare the concentrations of AZAs in our study 
Table 1 Physicochemical properties of azaarenes $\left(25^{\circ} \mathrm{C}\right.$, $101.3 \mathrm{kPa}$ ) in comparison with related PAHs. All data were taken from the database of EPI-suiteTM 4.1 (http://www.epa.gov/opptintr/ exposure/pubs/episuitedl.htm). Data in italics were estimated while all others were experimental data

\begin{tabular}{llllll}
\hline Name & Mw [g/mol $]$ & $\begin{array}{l}\text { Water solubility } \\
{[\mathrm{mg} / \mathrm{L}]}\end{array}$ & Log Kow & $\begin{array}{l}\text { Vapor pressure } \\
{[\mathrm{Pa}]}\end{array}$ & Log Koa \\
\hline $\begin{array}{c}\text { Azaarenes } \\
\text { Quinoline }\end{array}$ & 129.16 & 6110 & 2.03 & 8 & 6.19 \\
$\begin{array}{c}\text { Benzo[h] } \\
\text { quinoline }\end{array}$ & 179.22 & 78.7 & 3.43 & 0.0291 & 8.578 \\
Acridine & 179.22 & 38.4 & 3.4 & 0.018 & 8.961 \\
Related PAHs & & & & & \\
Naphthalene & 128.18 & 31 & 3.3 & 11.3 & 5.19 \\
Phenanthrene & 178.24 & 1.15 & 4.46 & 0.016 & 7.57 \\
Anthracene & 178.24 & 0.0434 & 4.45 & 0.00087 & 7.55 \\
\hline
\end{tabular}

to those reported in other studies, (3) to explore the relationship between AZAs, their related PAHs, and carbon fractions reported in earlier studies, (4) to study the relationship between ambient meteorological conditions and the temporal variation of $\mathrm{PM}_{2.5}$-bound AZAs, and (5) To draw conclusions on the drivers of $\mathrm{PM}_{2.5}$-bound AZAs concentrations in comparison to other related PACs measured in the same samples (Bandowe et al. 2014a).

\section{Materials and methods}

\section{Sampling and laboratory analysis}

Sampling location and procedures were described in the previous paper (Bandowe et al. 2014a). In brief, 65 and $24 \mathrm{~h}$ $\mathrm{PM}_{2.5}$ samples were collected from the atmosphere of Xi'an $\left(33.29^{\circ} \mathrm{N}-34.44^{\circ} \mathrm{N}\right.$ and $107.40^{\circ} \mathrm{E}-109.49^{\circ} \mathrm{E}$, Fig. 1), China.

The city of Xi' an which has a population of ca. 8 million is the administrative capital of Shaanxi province. The $\mathrm{PM}_{2.5}$

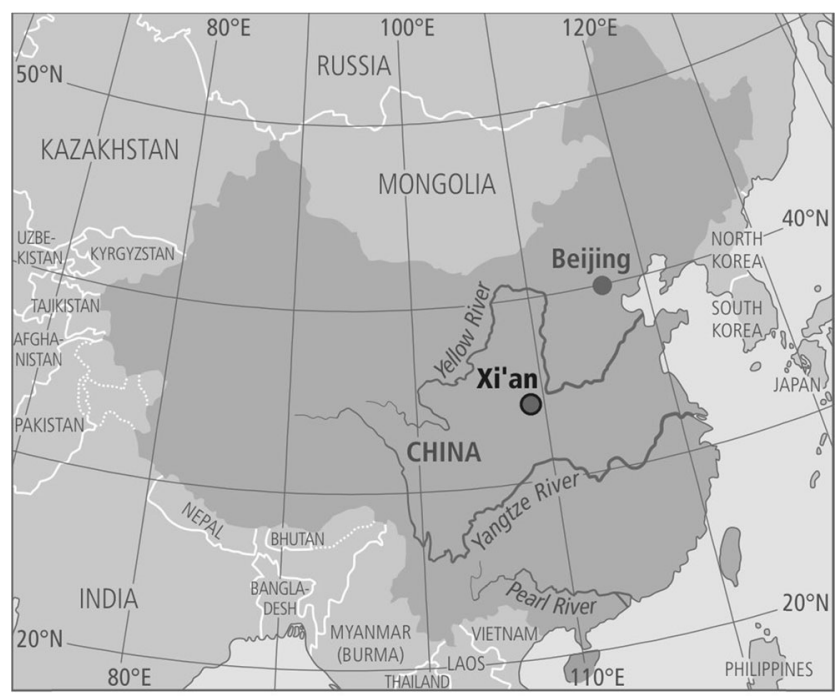

Fig. 1 Location of the sampling site in Xi'an, China sampler was placed at the top of the roof of the building of the Institute of Earth Environment, Chinese Academy of Sciences. Xi' an city center is about $15 \mathrm{~km}$ away from the sampling location (Cao et al. 2005; Dai et al. 2012; Bandowe et al. 2014a). One 24-h sample (10:00 to the next day 10:00) was collected every sixth day from 5 July, 2008 to 8 August 2009 on pre-baked $\left(780^{\circ} \mathrm{C}, 3 \mathrm{~h}\right)$ quartz-fiber filters (203 mm $\times 254 \mathrm{~mm}$, Whatman QM-A, USA) using TE6070MFC Hi-Vol $\mathrm{PM}_{2.5}$ air samplers (Tisch, OH, USA). The sampler was operated at a flow rate of $1 \mathrm{~m}^{3} \mathrm{~min}^{-1}$. All collected samples (filters with $\mathrm{PM}_{2.5}$ ) were immediately kept in cold storage (temperature $<-15^{\circ} \mathrm{C}$ ) until laboratory analysis. Ambient temperature (T), relative humidity $(\mathrm{RH})$, pressure (P), wind speed (WS), and wind direction (WD) were recorded during sampling. Further details about the sampling location and the health impact of PM on inhabitants of Xi' an were discussed in previous papers (Cao et al. 2005; Cao et al. 2012; Dai et al. 2012; Bandowe et al. 2014a). Properties such as mass of $\mathrm{PM}_{2.5}$, total carbon (TC), organic carbon (OC), EC, and other PACs (OPAHs, PAHs, and nitrated-PAHs) have previously been determined in the same set of samples (Bandowe et al. 2014a), and the procedures and results reported previously (Chow et al. 2007; Chow et al. 2011; Dai et al. 2012; Bandowe et al. 2014a).

\section{Analysis of $\mathbf{P M}_{2.5}$-bound AZAs}

The procedure for the analysis of $\mathrm{PM}_{2.5}$-bound AZAs was similar to those used for other PACs (PAHs and OPAHs) (Bandowe and Wilcke 2010; Bandowe et al. 2014a; Bandowe et al. 2014b; Lundstedt et al. 2014). In brief, AZAs (together with PAHs, OPAHs, and nitrated-PAHs) were extracted from the $\mathrm{PM}_{2.5}$ samples (on filters) and blank filters by pressurized liquid extraction after being spiked with internal standards. Each sample was extracted twice using dichloromethane. After that, the two extracts from each sample were combined, spiked with toluene as keeper, rotary evaporated, and transferred to $2 \mathrm{ml} \mathrm{GC}$ vials. Analytes were then measured by gas chromatography mass spectrometry (GC-MS) in the 
selected ion monitoring mode. Target AZAs [quinoline (QUI), benzo[h]quinoline (BQI) and acridine (ACR)] were identified using their retention times, ratios of quantifying and qualifier ions as compared to those in calibration standards measured together with the samples in same GC-MS sequence. AZAs were quantified by the internal standard method. Target and qualifier ions (SIM ions) used during GC-MS measurements are same as in previous reports (Bandowe and Wilcke 2010; Bandowe et al. 2014a; Bandowe et al. 2014b; Lundstedt et al. 2014). The mass of target compounds measured in blanks (which was insignificant) was deducted from the mass measured in samples (to correct for artifacts).

To check for the accuracy and precision of the analytical procedures, we spiked blank filters $(n=3)$ with target AZAs (at ca. $1000 \mathrm{ng}$ ) and applied the entire analytical procedure to it and then calculated the recovery of the target compounds as indicator of accuracy and the relative standard deviation as indication of the precision of the measurements. The average recoveries of the AZAs were $75 \pm 5,87 \pm 6,54 \pm 5 \%$ for QUI, $\mathrm{BQI}$, and ACR, respectively. The relative standard deviation (RSD) for the replicate $(n=3)$ measurements of each target AZA compound was $7-10 \%$ indicating the high precision of our measurements. The detection limit of our analytical method (LOD) was calculated as mass of target compound that produces a signal that is three times the baseline noise in the chromatogram. Concentrations lower than the LOD were designated as non-detected (n.d).

\section{Data evaluation and statistical analyses}

Based on the climate of Xi'an, the months of March, April, and May constitute the spring season; June, July, and August constitute the summer season; and September, October, and November constitute fall season while the months of December, January, and February constitute winter season (Dai et al. 2012). The sum of the three analyzed AZAs was called $\sum$ AZAs. The sum of the concentration of all analyzed PAHs is designated as $\sum 26 \mathrm{PAHs}$. Naphthalene, phenanthrene, anthracene, and benzo[a]pyrene are symbolized by as NAPH, PHEN, ANTH, and BaP, respectively. The sum of fluoranthene, pyrene benzo[a]anthracene, chrysene, benzo $[b+j+$ $\mathrm{k}]$ fluoranthene, benzo[e]pyrene, benzo[a]pyrene, indeno[1,2, 3-cd]pyrene, benzo[g,h,i]perylene, and coronene which mainly originate from combustion sources are referred to as CCOMB-PAHs (Bandowe et al. 2011). NAPH, PHEN, and ANTH are designated as PAHs related (related PAHs) to QUI, $\mathrm{BQI}$, and ACR, respectively, because of their structural similarity (Fig SI, Table 1). Concentrations of all PAHs used in the current work were taken from the previously published paper (Bandowe et al. 2014a). Statistical evaluations (Pearson's correlation and regression analysis, $t$ tests, ANOVA, and Tukey's HSD post hoc tests) were conducted on concentration data that have been mathematically transformed to improve their normal distribution. Concentration data sets were transformed using the formula $\log (\mathrm{x}+1)$, where $x$ is concentration. Statistical analyses were done with SPSS 19.0. The statistical tests were deemed to be significant at $p<0.05$.

\section{Results and discussion}

\section{Temporal and seasonal variation in concentrations of PM $_{2.5}$-bound AZAs}

The concentration of the $\sum$ AZAs in $\mathrm{PM}_{2.5}$ for the 14 months sampling period were $213-6440 \mathrm{pg} \mathrm{m}^{-3}$ (Fig. 2). The mean concentration of individual AZAs for the whole sampling period increased in the order QUI (mean $254 \mathrm{pg} \mathrm{m}^{-3}$, range 185$\left.520 \mathrm{pg} \mathrm{m}^{-3}\right)<\mathrm{BQI}\left(669 \mathrm{pg} \mathrm{m}^{-3}\right.$, range $69-$ $\left.2480 \mathrm{pg} \mathrm{m}^{-3}\right)<\mathrm{ACR}\left(757 \mathrm{pg} \mathrm{m}^{-3} 10-3540 \mathrm{pg} \mathrm{m}^{-3}\right)$ (Table S1). Very few studies have been conducted on AZAs in atmospheric $\mathrm{PM}_{2.5}$ (Lintelmann et al. 2010; Table 2). Compared to the measurements from other cities, the concentrations of individual AZAs and $\Sigma$ AZAs from this study were

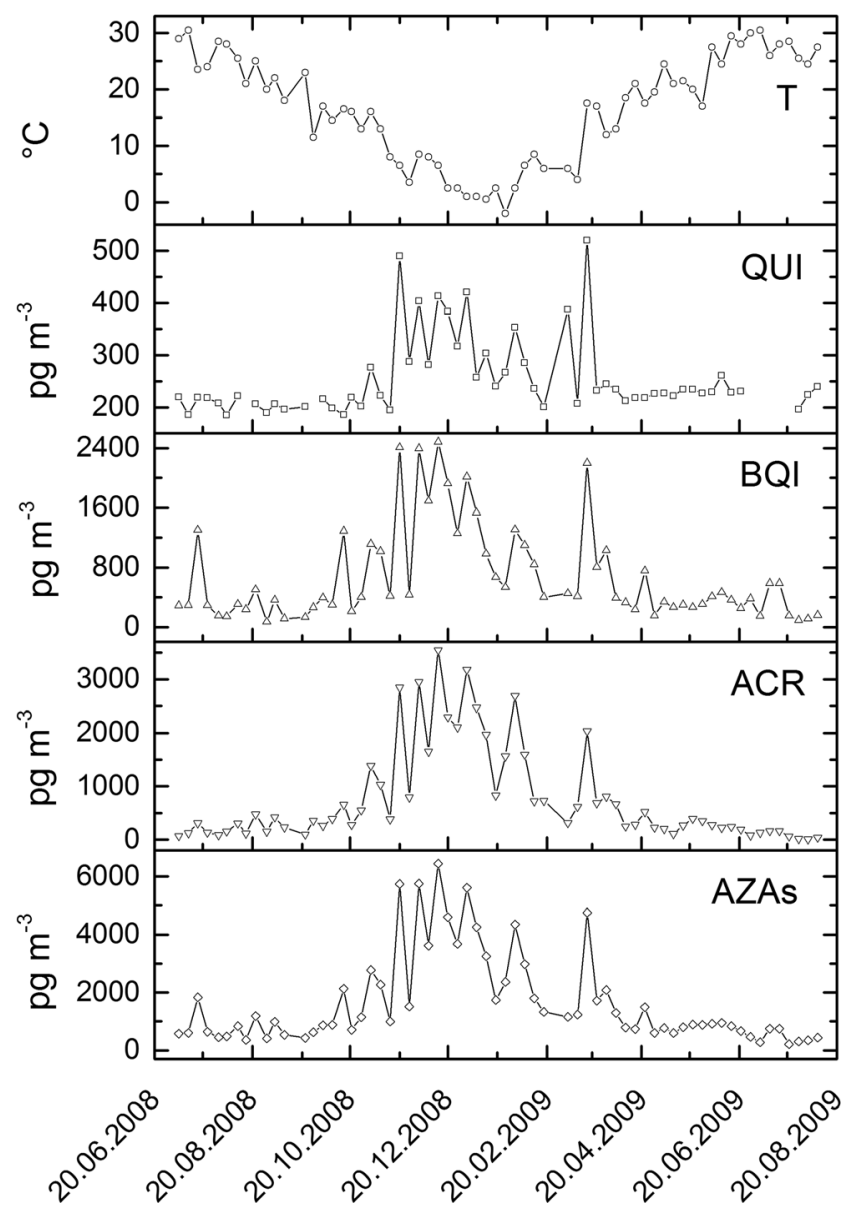

Fig. 2 Relationships between ambient temperature (T) and QUI, BQI, $\mathrm{ACR}$, and $\sum \mathrm{AZA}$ concentrations in $\mathrm{PM}_{2.5}$ of $\mathrm{Xi}$ 'an sampled from 5 July 2008 to 8 August 2009 
Table 2 Concentrations [pg m${ }^{-3}$ ] of particle-bound azaarenes in Xi' an, China in comparison with other geographic locations

\begin{tabular}{|c|c|c|c|c|c|c|c|c|}
\hline Location & Date & Particle size & Typology & Quinoline & Benzo[h]quinoline & Acridine & $\sum \mathrm{AZA}$ & Reference \\
\hline Xi'an, China & Winter 08/09 & $\mathrm{PM}_{2.5}$ & Urban & $201-420$ & $402-2483$ & $720-3544$ & $\begin{array}{c}1329-6411 \\
(n=3)\end{array}$ & This study \\
\hline Xi'an, China & Summer 08/09 & $\mathrm{PM}_{2.5}$ & Urban & $185-261$ & $69-1304$ & $10-477$ & $213-1833(n=3)$ & This study \\
\hline Algiers, Algeria & Winter 05/06 & $\mathrm{PM}_{10}$ & Urban & & & $290-420$ & $570-1100(n=2)$ & Ladji et al. 2009 \\
\hline Algiers, Algeria & Summer 05/06 & $\mathrm{PM}_{10}$ & Urban & & & nd-30 & $0.0-30(n=2)$ & Ladji et al. 2009 \\
\hline NY, USA & Feb-Apr/75 & TSP & Urban & 69 & 10 & 41 & $1244(n=21)$ & Dong et al. 1977 \\
\hline NY, USA & Jan-Mar/76 & TSP & Urban & 22 & 13 & 40 & $716(n=21)$ & Dong et al. 1977 \\
\hline $\begin{array}{l}\text { Copenhagen, } \\
\text { Denmark }\end{array}$ & Winter 76-82 & $\mathrm{PM}_{1.2}$ & Residential & 110 & 200 & & $960(n=11)$ & Nielsen et al. 1986 \\
\hline $\begin{array}{l}\text { Copenhagen, } \\
\text { Denmark }\end{array}$ & Winter 76-82 & $\mathrm{PM}_{1.2}$ & Traffic & 400 & 300 & & $1275(n=11)$ & Nielsen et al. 1986 \\
\hline $\begin{array}{l}\text { Münich, } \\
\text { Germany }\end{array}$ & Winter 08 & $\mathrm{PM}_{2.5}$ & Suburban & & & 356 & $120-600(n=10)$ & Lintelmann et al. 2010 \\
\hline $\begin{array}{l}\text { Upper Silesia, } \\
\text { Poland }\end{array}$ & Summer 91 & TSP & Industrial & & $390(220-600)$ & $678(530-1000)$ & $\begin{array}{c}1190-2290 \\
(n=5)\end{array}$ & Warzecha 1993 \\
\hline $\begin{array}{l}\text { Strasbourg, } \\
\text { France }\end{array}$ & Annual 06/07 & $\mathrm{PM}_{10}$ & Urban & & & & $2800(n=19)$ & $\begin{array}{l}\text { Delhomme and Millet } \\
2012\end{array}$ \\
\hline Besancon, France & Annual 06/07 & $\mathrm{PM}_{10}$ & Urban & & & & $1600(n=19)$ & $\begin{array}{l}\text { Delhomme and Millet } \\
2012\end{array}$ \\
\hline $\begin{array}{l}\text { Spicheren, } \\
\text { Germany }\end{array}$ & Annual 06/07 & $\mathrm{PM}_{10}$ & Urban & & & & $1000(n=19)$ & $\begin{array}{l}\text { Delhomme and Millet } \\
2012\end{array}$ \\
\hline Liverpool, UK & Annual 94-96 & TSP & Urban & & $27(6-152)$ & $176(22-523)$ & $2800(n=47)$ & Chen and Preston 1998 \\
\hline Liverpool, UK & Winter 94-96 & TSP & Urban & & & & $6240(n=47)$ & Chen and Preston 1998 \\
\hline Liverpool, UK & Summer 94-96 & TSP & Urban & & & & $480(n=47)$ & Chen and Preston 1998 \\
\hline
\end{tabular}

either comparable or higher than at the other locations (Table 2, Table S1). The concentrations of AZAs in $\mathrm{PM}_{2.5}$ samples have never been reported from any location in China. However, the fact that the concentrations of AZAs in Xi'an are higher than in urban areas of Western Europe and USA (Table 2) is in line with findings for other PACs. PACs such as PAHs, OPAHs, and nitrated-PAHs in air PM from Chinese cities are of similarly higher concentrations than in air PM sampled from Western Europe, Japan, and North America (Wang et al. 2006; Bandowe et al. 2014a).

The concentrations of $\sum A Z A s$, individual AZAs, and their composition pattern showed a seasonal variation. Mean concentration of $\sum$ AZAs was highest in winter and lowest in summer (i.e., winter $>$ fall $>$ spring $>$ summer; Fig. 2). The mean concentration of $\sum$ AZAs in winter was significantly higher than that in fall, summer, and spring (ANOVA with Tukey's HSD test). The ratio of the concentration of $\sum$ AZAs in winter to that in summer (W/S) averaged 5.7. The concentrations of individual AZAs showed similar trend (i.e., highest concentration in winter and lowest concentration in summer) as the $\sum$ AZAs (Fig. 2, Table S1). The average W/S was 1.4, 4.1, and 13 for QUI, BQI, and ACR, respectively. A previous study from Strasbourg (France) found the W/S ratio of 9.2, 7.3, 41, and 3.2 for two-, three-, four-, and five-ring AZAs, respectively, which is in line with our study (Delhomme and Millet 2012). The seasonal variation in our AZA concentration is consistent with most previous studies which also report higher average concentrations in winter seasons than in summer seasons (Chen and Preston 1998; Ladji et al. 2009;
Delhomme and Millet 2012). This trend reflect increased tendency of AZAs (like other PACs) to condense into the particle phase during the winter months because of the lower ambient temperature, a lower inversion layer height, higher mass of total suspended particles, higher PACs emissions (from increased household heating), and a lower photo degradation than in summer (Bandowe et al. 2014a; Chen and Preston 1998; Ladji et al. 2009; Delhomme and Millet 2012). Chen and Preston (1997) have shown that the percentage of AZAs in particulate phase of air was $30 \%$ in summer and $70 \%$ in winter hence strongly suggesting that larger partitioning into the particulate phase during winter is a reason for the increase in AZAs concentrations in winter. Elevated contribution of fine PM to the total atmospheric PM and lower redistribution of AZAs to larger particles in winter compared to summer fraction are further factors that contribute to the higher concentrations of $\mathrm{PM}_{2.5}$-bound AZAs in winter compared to summer (Chen and Preston 1997; Chen and Preston 1998; Albinet et al. 2008; Ringuet et al. 2012).

The average composition pattern of the AZA mixtures for the whole sampling period was dominated by BQI (mean $42 \%$, range $17-48 \%)>$ ACR $(38 \%, 3-66 \%)>$ QUI (21\%, 0-65\%). The seasonal contributions of the individual compounds to the $\Sigma$ AZAs followed the order, ACR (54\%)> BQI $(35 \%)>$ QUI $(6 \%)$ in winter and BQI $(49 \%)>$ QUI $(27 \%)>$ ACR $(24 \%)$ in summer (Fig. 3). Hence, the composition pattern of AZAs in $\mathrm{PM}_{25}$ of Xi'an's atmosphere was in all cases dominated by the three-ring AZAs, followed by the two-ring AZA. 
In contrast, the composition pattern of AZAs from several European and North American cities (Liverpool, Strasbourg, Spicheren, Besancon, Copenhagen, and New York) showed increasingly lower contributions to $\sum$ AZAs concentrations with increasing ring size (Dong et al. 1977; Chen and Preston 1998; Delhomme and Millet 2012). However, in an industrialized area of Upper Silesia, Poland (where coal is extensively used), the concentration of 3-ring AZAs (ACR and BQI) was also higher than those of two-ring AZAs (Warzecha 1993). We therefore attribute the dominance of three- over two-ring AZAs in the Xi'an samples compared to the other cities (Liverpool, Strasbourg, Spicheren, Besancon, Copenhagen, and New York) as indication of greater use of coal in Xi'an, where the fossil fuel used for energy (which amounts to $4.905 .405 \mathrm{t}$ of standard coal equivalent) includes $58 \%$ of coal and $25 \%$ of oil (Xi'an Municipal Statistics Bureau 2011). Coal combustion is known to produce both larger concentrations of AZAs as well as higher contributions of higher ring size AZAs to the total AZA concentration (Dong et al. 1977; Wakeham 1979; Warzecha 1993; Osborne et al. 1997; Chen and Preston 1998). The higher molecular weight and lower vapor pressure of ACR (Table 1, Figure S1) will also lead to its more pronounced partitioning into the particulate phase, hence its higher contribution to $\Sigma$ AZAs concentrations than of the low molecular weight QUI. The seasonal change in the dominant AZA may also be an indication of the increased emission of ACR from household combustion of coal (for heating) during winter season.

There was significant correlation $(p<0.05)$ of the concentrations of individual AZAs with each other (Table S2). The correlation between QUI and BQI $(r=0.713, p<0.01)$ and ACR $(r=0.653, p<0.01)$ was weaker than the correlation between BQI and ACR $(r=0.849, p<0.01)$. In comparison, the concentrations of the three-ring PAHs (PHEN and ANTH, taken from previous paper, Bandowe et al. 2014a) were correlated with each other $(r=0.966, p<0.01)$ but not with the two-ring PAH, NAPH (Table S2). Correlations between twoand three-ring AZAs ( $r=0.82$ and 0.89$)$ were observed in the atmosphere of the Strasbourg region (France) and Liverpool (England), respectively (Chen and Preston 1998; Delhomme and Millet 2012). In Munich (Germany), the correlation coefficient between individual $\mathrm{PM}_{2.5}$-bound AZAs sampled in winter was $>0.9$ (Lintelmann et al. 2010). Such strong correlations between individual AZAs result from their common source, co-sorption, and/or similar fates in outdoor atmospheric environment (Osborne et al. 1997; Chen and Preston 1998; Chen et al. 2008). The weaker correlation between QUI and the three-ring AZAs could be explained by differences in their physicochemical properties and thus gas/particle partitioning (Table 1, Chen and Preston 1997, 1998 and 2004).

\section{Relationship between AZAs, PAHs, mass of $\mathbf{P M}_{2.5}$, and carbon}

The average individual AZA/related PAH concentration ratios calculated in the current study were QUI/NAPH (mean 1.64, range 0.37-10), BQI/PHEN (mean 0.36, range 0.03-1.67), and ACR/ANTH (mean 1.43, range 0.23-3.5) (Fig. 4). This is in contrast to previous reports that suggest that the concentrations of AZAs in environmental media are frequently about $1-10 \%$ of those of their related PAHs (Bleeker et al. 2002: Lintelmann et al. 2010).

The percent number of days for which the individual AZA/ related $\mathrm{PAH}$ ratio was $>1$ and was 56,6 , and $68 \%$ for QUI/ NAPH, BQI/PHEN, and ACR/ANTH, respectively. These enhanced concentrations of AZAs relative to their related PAHs which are in contrast to studies from Western Europe and USA are an additional reflection of the higher proportion of coal in the fossil fuel use profile of Xi'an. Enhanced concentrations of AZAs relative to PAHs have also been observed in European regions where coal is dominantly used as industrial fuel or for power plants or in European cities with less efficient combustion of coal (e.g., Krakow, Poland) for residential heating (Warzecha 1993; Junninen et al. 2009). AZAs are considered as markers for coal combustion (Junninen et al. 2009). Bi et al. (2008) suggested that the higher concentrations of organic nitrogen in coal used in China might favor the formation and emission of high concentrations of AZAs during their combustion. Furthermore, there might also be a distinct influence of biomass burning which is more pronounced in China than most developed countries (Xu et al. 2006; Shen et al. 2013). Concentration of individual AZAs was higher
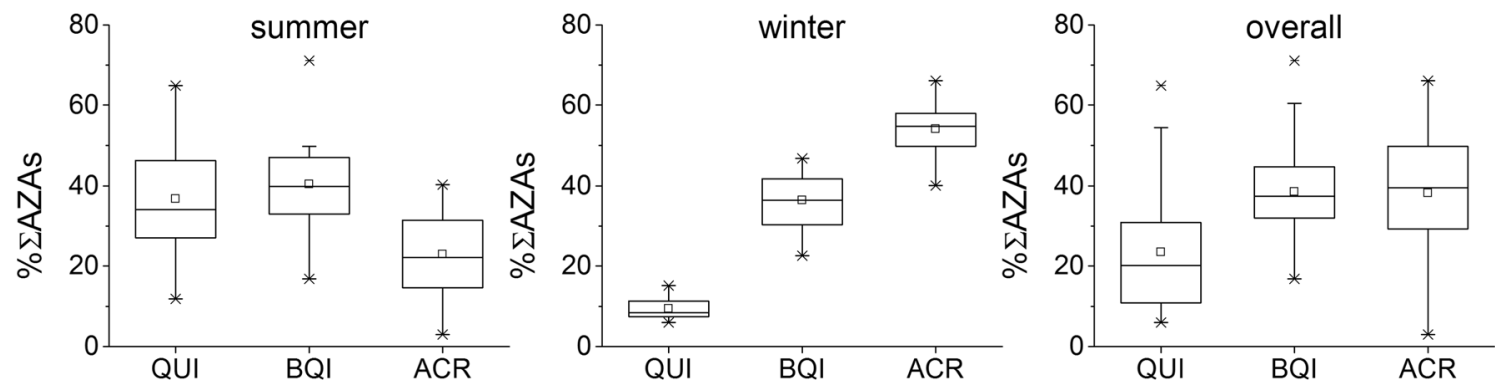

Fig. 3 Composition pattern of AZAs in $\mathrm{PM}_{2.5}$ of Xi'an 


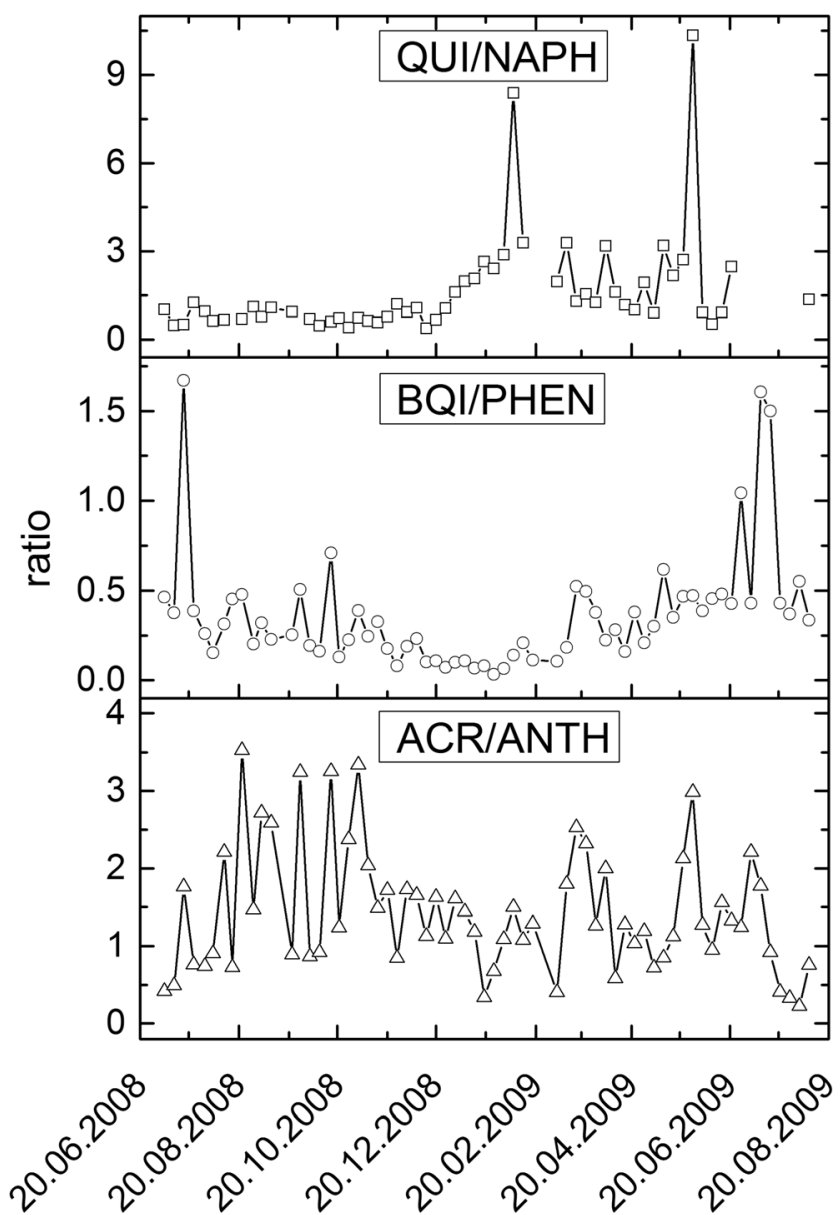

Fig. 4 Concentration ratio of AZAs to their related PAHs in $\mathrm{PM}_{2.5}$ of Xi'an

than their related PAHs in soils of Bangkok (Thailand) which could be related with enhanced biomass burning (Shen et al. 2013; Bandowe et al. 2014b).

The concentrations of three-ring AZAs were correlated with their related PAHs [i.e., BQI vs PHEN $(r=0.806$, $p<0.01)$ and ACR vs ANTH $(r=0.878, p<0.01)]$ while the two-ring QUI did not significantly correlate with NAPH (Fig. 5). The concentrations of individual AZAs and $\sum A Z A s$ also correlated significantly with the concentrations of $\sum$ 26PAHs, $\sum$ COMB-PAHs, and BaP (Fig. 5, Table S2) reported in Bandowe et al. (2014a). Such strong relationships between AZAs and related PAHs indicate common sources (pyrogenic combustion activities), and similarity in post-emission transport and environmental turnover. We previously found similar relationships between other polar PACs (OPAHs and nitrated PAHs) and PAHs in this same set of samples which were also attributed to their common source, similar transport mechanisms, and atmospheric turnover (Bandowe et al. 2014a).

The concentration of total carbon (TC), elemental carbon (EC), and organic carbon (OC) in atmospheric PM is frequently found to be strongly correlated with non-ionizable polar and hydrophobic PACs because of their co-emission, co-sorption, transport, and similar fate (Pankow and Bidleman 1991; Cao et al. 2009; Li et al. 2009; Ma et al. 2013; Bandowe et al. 2014a). The concentrations of each AZA were correlated with EC, OC, and $\mathrm{PM}_{2.5}$ (Fig. 6, Table S2). Correlations between three-ring $\mathrm{AZA}$ and $\mathrm{OC}, \mathrm{EC}$, and $\mathrm{PM}_{2.5}$ were stronger than with those of the two-ring AZA (QUI) and OC, EC, and $\mathrm{PM}_{2.5}$, which was also earlier observed for the related PAHs (Table S2, Bandowe et al. 2014a). This is attributable to the higher vapor pressure of QUI and the higher fraction of it in the gaseous phase compared to the three-ring AZAs (Chen and Preston 1997). Individual AZAs were more strongly correlated OC than with EC. Similar pattern was also observed for their related PAHs and other PACs (OPAHs and nitratedPAHs, Bandowe et al. 2014a, Table S2). It was the working hypothesis of this study that there will be significant differences between AZAs and their related PAHs with regards to the relationship between each compound group and the components of atmospheric $\mathrm{PM}$ (mass of $\mathrm{PM}_{2.5}, \mathrm{EC}, \mathrm{OC}$, and TC). This is because the physicochemical properties of AZAs (ability to form ions under changing atmospheric $\mathrm{pH}$, ability to be sorbed to minerals because of their higher charge density/ionic forms which enables them to form specific bonds with minerals particle in atmospheric aerosols, and their higher water solubility) are different from the more hydrophobic and neutral PAHs (Götz et al. 2007; Arp et al. 2008; Bandowe et al. 2014a). In contrast to our hypothesis, our results strongly suggest that the relationships between AZAs and atmospheric sorbents $\left(\mathrm{PM}_{2.5}\right.$ and carbonaceous matter) are similar to the relationship between hydrophobic PAHs and atmospheric sorbents ( $\mathrm{PM}_{2.5}$ and carbonaceous matter). This finding strongly suggests that the physical, chemical, and ionic properties of AZAs do not significantly lead to a deviation in terms of their sorption properties compared to the neutral and more hydrophobic PACs. Further investigations on the relationships between atmospheric sorbents and higher molecular weight AZAs are warranted because the differences in sorption mechanism and extent of sorption could become more visible with increasing molecular weight. Previous studies have suggested that the sorption mechanisms and partitioning properties of AZAs might be similar to those of PAHs (Chen and Preston 1997).

\section{Relationship between ambient meteorological conditions and $\mathrm{PM}_{2.5}$-bound AZAs}

The concentrations of QUI, BQI, ACR, and AZAs increased with decreasing ambient $\mathrm{T}$ and WS (significant negative correlation, Fig. 2, Table S2), but increased with increasing ambient $\mathrm{P}$ (significant positive correlation, Table S2). The concentration of QUI decreased with increasing RH (significant negative correlation, Table S2). There were slight differences between some individual AZAs and their related PAHs. For 

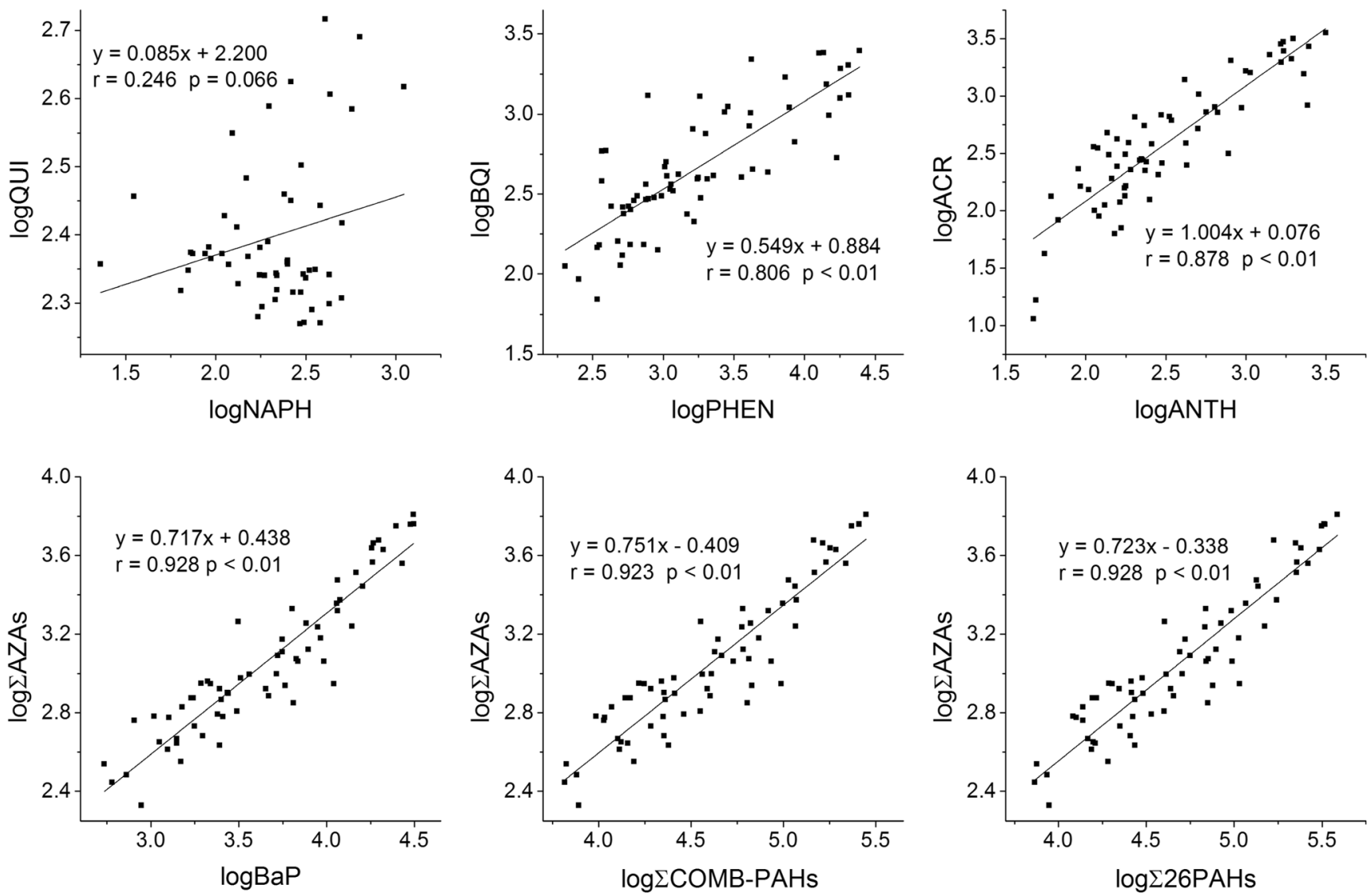

Fig. 5 Correlation of $\log (\mathrm{x}+1)$-transformed concentration of AZAs and PAHs in $\mathrm{PM}_{2.5}$ of Xi'an

instance, there was no significant relationship between NAPH concentrations in $\mathrm{PM}_{2.5}$ and any meteorological parameter while the concentrations QUI (the NAPH-related AZA) were significantly correlated with T, P, RH, and WS (Table S2). Furthermore, there was no significant relationship between $\mathrm{RH}$ and $\mathrm{BQI}$ and $\mathrm{ACR}$ concentrations, but RH was negatively correlated with the concentrations of the BQI- and ACRrelated PAHs (PHEN and ANTH). We previously also found significant correlations between several PAHs, OPAHs, nitrated-PAHs, and meteorological parameters for the same $\mathrm{PM}_{2.5}$ samples (Bandowe et al. 2014a). Studies that investigated annual concentrations of AZAs in European cities (Liverpool, Strasbourg, Besançon, and Spicheren) found negative correlations between ambient $\mathrm{T}$ and concentrations of AZAs ( $r=-0.5$ to -0.88 ) in PM (Chen and Preston 1998; Delhomme and Millet 2012). The inverse relationship between ambient $\mathrm{T}$ and AZAs concentrations can be attributed to higher AZAs emissions during colder periods because of enhanced household heating, less degradation because of lower heat and sunlight, lower average $\mathrm{OH}$ radical concentration in the atmosphere, enhanced partitioning onto atmospheric PM, and smaller redistribution to coarser particles (Yamasaki et al. 1982; Chen and Preston 1997; Chen and Preston 1998; Tsapakis and Stephanou 2005). The inverse relationship between WS and $\mathrm{PM}_{2.5}$-bound AZAs concentrations results from the fact that higher WS dilutes and disperses AZAs (Mastral et al. 2003; Amodio et al. 2009; Cao et al. 2009: Gu et al. 2010; Bandowe et al. 2014a). High ambient P often results in stable and calm ambient atmospheric conditions such as low WS, stable atmospheric stratification, and narrower atmospheric mixing layer height (Tsai 2005; Akyüz and Çabuk 2009). These conditions results in lower dispersion of PM-bound AZAs and hence higher concentrations (Tsai 2005; Akyüz and Çabuk 2009; Zhou et al. 2013; Bandowe et al. 2014a; Li et al. 2015). A winter-time study in Munich found that AZAs concentrations were higher in days without rain or snow (Lintelmann et al. 2010).

\section{Conclusions}

The $\mathrm{PM}_{2.5}$-bound concentrations of individual AZAs from Xi'an, China are higher than those reported from North American and Western European cities. Individual AZA concentrations were frequently higher than those of their regulated and related PAHs. There was a dominance of three-ring AZAs over two-ring AZAs. The more pronounced use of coal

Fig. 6 Relationship between $\log (x+1)$-transformed carbon fractions and mass of $\mathrm{PM}_{2.5} \log (\mathrm{x}+1)$-transformed concentrations of AZAs 

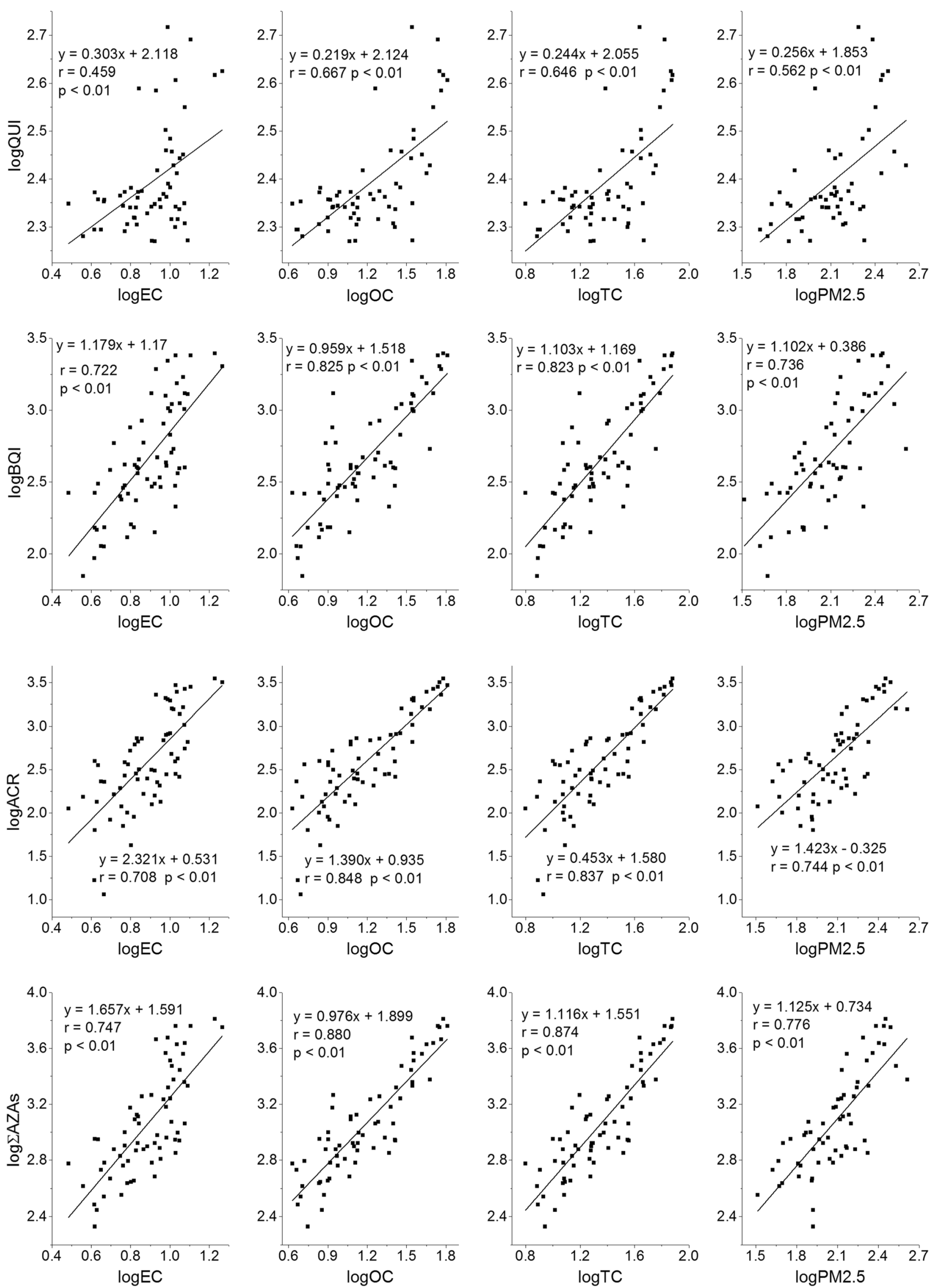
in Xi'an compared to Western countries is a likely explanation for the contrasts between the results from Xi'an and Western countries. Concentrations of AZAs showed positive correlations with the concentrations of $\mathrm{PM}_{2.5}, \mathrm{EC}, \mathrm{OC}$, and their related PAHs, indicating similar sources and fates. Concentrations of AZAs in $\mathrm{PM}_{2.5}$ also showed strong negative correlations with T, WS, and positive relationship with $\mathrm{P}$ which is related to enhanced emissions, enhanced gas/particle partition and retention onto $\mathrm{PM}_{2.5}$, lower degradation during colder months and lower dispersion/dilution during periods of lower WS, and stable atmospheric conditions. The findings strongly suggest that the fate of AZAs is similar to that of their related PAHs in spite of their significantly different physicochemical properties.

Acknowledgment This project was funded with grants from the Swiss National Science Foundation (SNF 200021_131938/1) and the Chinese Academy of Science "Strategic Priority Research Program" (XDB05060500). We thank Wolfgang Wilcke (Karlsruhe Institute of Technology (KIT), Germany) for his support. We thank Alexander Herrmann (Institute of Geography, University of Bern) for drawing Fig. 1.

\section{References}

Albinet A, Leoz-Garziandia E, Budzinski H, Villivave E, Jaffrezo J-L (2008) Nitrated and oxygenated derivatives of polycyclic aromatic hydrocarbons in the ambient air of two French alpine valleys part 2: particle size distribution. Atmospheric Environment 42:55-64

Akyüz M, Çabuk H (2009) Meteorological variations of $\mathrm{PM}_{2.5} / \mathrm{PM}_{10}$ concentrations and particle-associated polycyclic aromatic hydrocarbons in the atmopheric environment of Zonguldak, Turkey. Journal of Hazardous Materials 170:13-21

Amodio M, Caselli M, de Gennaro G, Tutino M (2009) Particulate PAHs in two urban areas of Southern Italy: impact of the sources, meteorological and background conditions on air quality. Environmental Research 109:812-820

Arp HPH, Schwarzenbach RP, Goss KU (2008) Ambient gas/particle partitioning. 1. Sorption mechanisms of apolar, polar, and ionizable organic compounds. Environmental Science \& Technology 42: $5541-5547$

Bandowe BAM, Sobocka J, Wilcke W (2011) Oxygen-containing polycyclic aromatic hydrocarbons (OPAHs) in urban soils of Bratislava, Slovakia: patterns, relation to PAHs and vertical distribution. Environmental Pollution 159:539-549

Bandowe BAM, Wilcke W (2010) Analysis of polycyclic aromatic hydrocarbons and their oxygen-containing derivatives and metabolites in soils. Journal of Environmental Quality 39:1349-1358

Bandowe BAM, Meusel H, Huang R-J, Ho KF, Cao JJ, Hoffmann T, Wilcke W (2014a) PM $_{2.5}$-bound oxygenated PAHs, nitro-PAHs and parent-PAHs from the atmosphere of a Chinese megacity: seasonal variation, sources and cancer risk assessment. Science of the Total Environment 473-474:77-87

Bandowe BAM, Lueso MG, Wolfgang W (2014b) Oxygenated polycyclic aromatic hydrocarbons and azaarenes in urban soils: a comparison of a tropical city (Bangkok) with two temperate cities (Bratislava and Gothenburg). Chemosphere 107:407-414

Bi E, Schmidt TC, Haderlein SB (2006) Sorption of heterocyclic organic compounds to reference soils: column studies for process identification. Environmental Science \& Technology 40:5962-5970
Bi X, Simoneit BRT, Sheng G, Fu J (2008) Characterization of molecular markers in smoke from residential coal combustion in China. Fuel $87: 112-119$

Bleeker EAJ, Wiegman S, de Voogt P, Kraak M, Leslie HA, de Haas, Admiraal W (2002) Toxicity of azaarenes. Reviews of Environmental Contamination and Toxicology 173:39-83

Boström CE, Gerde P, Hanberg A, Jernström B, Johansson C, Kyrklund T, Rannug A, Tornquist M, Victorin K, Westerholm R (2002) Cancer risk assessment, indicators, and guidelines for polycyclic aromatic hydrocarbons in the ambient air. Environmental Health Perspectives 110:451-488

Cao J, Wu F, Chow JC, Lee SC, Li Y, Chen SW, An ZS, Fung KK, Watson JG, Zhu CS, Liu SX (2005) Characterization and source apportionment of atmospheric organic and elemental carbon during fall and winter of 2003 in Xi'an, China. Atmospheric Chemistry \& Physics 5:3127-3137

Cao JJ, Zhu CS, Chow JC, Watson JG, Han YM, Wang GH, Shen ZX, An ZS (2009) Black carbon relationships with emissions and meteorology in Xi'an, China. Atmospheric Research 94:194-202

Cao JJ, Xu HM, Xu Q, Chen BH, Kan HD (2012) Fine particulate matter constituents and cardiopulmonary mortality in a heavily polluted Chinese city. Environmental Health Perspectives 120:373-378

Chan CK, Yao X (2008) Air pollution in megacities in China. Atmos Environ 42:1-42

Chen HY, Preston MR (1997) Gas/particle partitioning behaviour of azaarenes in an urban atmosphere. Environmental Pollution 97: 289-298

Chen HY, Preston MR (1998) Azaarenes in the aerosol of an urban atmosphere. Environment Science \& Technology 32:577-583

Chen HY, Preston MR (2004) Dissolution of azaarenes from urban aerosols. Atmospheric Environment 38:1023-1028

Chen HY, Su CC, Hung CC, Yeh TC, Shen YH, Tsai CH, Chen LD, Gong GC (2008) Occurrence of azaarenes in Sediments of the Danshuei River, Taiwan - the use of azaarenes as indicator of anthropogenic source to the estuarine system. Environ Toxicol 23:2535

Chow JC, Watson JG, Chen LWA, Chang MCO, Robinson NF, Trimble D, Kohl S (2007) The IMPROVE-A temperature protocol for thermal/optical carbon analysis: maintaining consistency with a long-term database. Journal of Air \& Waste Management Association 57:1014-1023

Chow JC, Watson JG, Robles J, Wang XL, Chen LWA, Trimble DL, Kohl SD, Tropp RJ, Fung KK (2011) Quality assurance and quality control for thermal/optical analysis of aerosol samples for organic and elemental carbon. Analytical and Bioanaytical Chemistry 401: 3141-3152

Collins J, Brown J, Alexeeff G, Salmon A (1998) Potency equivalency factors for some polycyclic aromatic hydrocarbons and polycyclic aromatic hydrocarbon derivatives. Regulatory Toxicology and Pharmacology 28:45-54

Dai WT, Ho SSH, Ho KF, Cao JJ (2012) Characterization of particulatephase high molecular weight mono-carbonyls $(\mathrm{C \#}>5)$ and dicarbonyls in urban atmosphere of Xi'an, China. Aerosol and Air Quality Research 12:892-901

Delhomme O, Millet M (2012) Azaarenes in atmospheric particulate matter samples of three different urban sites in east of France. Atmospheric Environment 47:541-545

Dong MW, Locke DC, Hoffmann D (1977) Characterization of azaarenes in basic organic portion of suspended particulate matter. Environmental Science \& Technology 11:612-618

European Union (2005) Directive 2004/107/EC of the European Parliament and the Council of 15 December 2004 relating to arsenic, cadmium, mercury, nickel and polycyclic aromatic hydrocarbons in ambient air. Off J Eur Union 23:3-16

Gerlofs-Nijland ME, Rummelhard M, Boere AJF, Leseman DLAC, Duffin R, Schins RPF, Borm, Paul JA, Sillanpää M, Salonen RO, 
Cassee FR (2009) Particle induced toxicity in relation to transition metal and polycyclic aromatic hydrocarbon contents. Environmental Science \& Technology 43:4729-4736

Götz CW, Scheringer M, Macleod M, Roth CM, Hungerbuehler K (2007) Alternative approaches for modeling gas-particle partitioning of semivolatile organic chemicals: model development and comparison. Environmental Science \& Technology 41:1272-1278

Gu Z, Feng J, Han W, Li L, Wu M, Fu J, Sheng G (2010) Diurnal variations of polycyclic aromatic hydrocarbons associated with $\mathrm{PM}_{2.5}$ in Shanghai, China. Journal of Environmental Science 22: 389-396

Harrison RM, Smith DJT, Kibble AJ (2004) What is responsible for the carcinogenicity of $\mathrm{PM}_{2.5}$ ? Occupational and Environmental Medicine 61:799-805

Harrison RM, Yin J (2000) Particulate matter in the atmosphere: which particle properties are important for its effects on health? The Science of the Total Environment 249:85-101

Huang RJ, Zhang YL, Bozzetti C, Ho KF, Cao JJ, Han YM, Daellenbach KR, Slowik JG, Platt SM, Canonaco F, Zotter P, Wolf R, Pieber SM, Bruns EA, Crippa M, Ciarelli G, Piazzalunga A, Schwikowski M, Abbaszade G, Schnelle-Kreis J, Zimmermann R, An ZS, Szidat S, Baltensperger U, El Haddad I, Prevot ASH (2014) High secondary aerosol contribution to particulate pollution during haze events in China. Nature 514:218-222

IARC (2011) Bitumens and bitumen emissions, and some N- and Sheterocyclic aromatic hydrocarbons. IARC Monographs on the Evaluation of Carcinogenic Risks to Humans 103:1-311

Jung DJK, Klaus T, Fent K (2001) Cytochrome P450 induction by nitrated polycyclic aromatic hydrocarbons, azaarenes, and binary mixtures in fish hepatoma cell line PLHC-1. Environmental Toxicology and Chemistry 20:149-159

Junninen H, Monster J, Rey M, Cancelinha J, Douglas K, Duane M, Forcina V, Müller A, Lagler F, Marelli L, Borowiak A, Niedzialek J, Paradiz B, Mira-Salama D, Jimenez J, Hansen U, Astorga C, Stanczyk K, Viana M, Querol X, Duvall RM, Norris GA, Tsakovski S, Wahlin P, Horak J, Larsen BR (2009) Quantifying the impact of residential heating on the urban air quality in a typical European coal combustion region. Environmental Science \& Technology 43:7964-7970

Kan H, Chen R, Tong S (2012) Ambient air pollution, climate change, and population health in China. Environment International 42:10 19

Kochany J, Maguire RJ (1994) Abiotic transformations of polynuclear aromatic hydrocarbons and polynuclear aromatic nitrogen heterocycles in aquatic environments. The Science of the Total Environment 144:17-31

Ladji R, Yassaa N, Balducci C, Cecinato C, Meklati BY (2009) Annual variation of particulate organic compounds in $\mathrm{PM}_{10}$ in the urban atmosphere of Algiers. Atmospheric Research 92:258-269

Li Y, Chen QL, Zhao HJ, Wang L, Tao R (2015) Variations in $\mathrm{PM}_{10}$, $\mathrm{PM}_{2.5}$ and $\mathrm{PM}_{1.0}$ in an urban area of the Sichuan Basin and their relation to meteorological factors. Atmosphere 6:150-163

Li Z, Sjödin A, Porter EN, Patterson DG Jr, Needham LL, Lee S, Russell AG, Mulholland JA (2009) Characterization of $\mathrm{PM}_{2.5}$-bound polycyclic aromatic hydrocarbons in Atlanta. Atmospheric Environment 43:1043-1050

Lintelmann J, FranÇa MH, Hubner E, Matuschek G (2010) A liquid chromatography-atmospheric pressure photoionization tandem mass spectrometric method for the determination of azaarenes in atmospheric particulate matter. Journal of Chromatography A 1217:1636-1646

Lundstedt S, Bandowe BAM, Wilcke W, Boll E, Christensen JH, Vila J, Grifoll M, Faure P, Biache C, Lorgeoux C, Larsson M, Frech Irgum K, Ivarsson P, Ricci M (2014) First intercomparison study on the analysis of oxygenated PAHs and nitrogen heterocyclic compounds
(N-PACs) in contaminated soil. Trends in Analytical Chemistry 57: 83-92

Ma J, Chen ZY, Wu MH, Feng JL, Horii Y, Ohura T, Kannan K (2013) Airborne $\mathrm{PM}_{2.5} / \mathrm{PM}_{10}$-associated chlorinated polycyclic aromatic hydrocarbons and their parent compounds in a suburban area in Shanghai, China. Environmental Science \& Technology 14:76157623

Machala M, Ciganek M, Blaha L, Minksova K, Vondrack J (2001) Aryl hydrocarbon receptor-mediated and estrogenic activities of oxygenated polycyclic aromatic hydrocarbons and azaarenes originally identified in extracts of river sediments. Environmental Toxicology and Chemistry 20:2736-2743

Mastral AM, López JM, Callén MS, García T, Murillo R, Navarro MV (2003) Spatial and temporal PAH concentrations in Zaragoza, Spain. Science of the Total Environment 307:111-124

Matus K, Nam KM, Selin NE, Lamsal LN, Reily JM, Paltsev S (2012) Health damages from air pollution in China. Global Environmental Change 22:55-66

Millman A, Tang D, Perera FP (2008) Air pollution threatens the health of children in China. Pediatrics 122:620-628

Ministry of Environmental Protection of The People's Republic of China (2012) Ambient air quality standards (GB-3095-2012, in Chinese). http://kjs.mep.gov.cn/hjbhbz/bzwb/dqhjbh/dqhjzlbz/201203/ W020120410330232398521.pdf

Nel A (2005) Air pollution-related illness: effects of particles. Science 308:804-806

Nielsen T, Clausen P, Jensen FP (1986) Determination of basic azaarenes and polynuclear aromatic hydrocarbons in airborne particulate matter by gas chromatography. Analytical Chimica Acta 187:223-231

Osborne PJ, Preston MR, Chen HY (1997) Azaarenes in sediment, suspended particles and aerosol associated with the River Mersey estuary. Marine Chemistry 58:73-83

Pankow JF, Bidleman TF (1991) Effects of temperature, TSP and percent non-exchangeable material in determining the gas-particle partitioning of organic compounds. Atmospheric Environment 25: 2241-2249

Pope III CA, Dockery DW (2006) Health effects of fine particulate air pollution: lines that connect. J Air Waste Manage Assoc 56:709-742

Ravindra K, Sokhi R, Van Grieken R (2008) Atmospheric polycyclic aromatic hydrocarbons: source attribution, emission factors and regulation. Atmospheric Environment 42:2895-2921

Reineke A-K, Göen T, Preiss A, Hollender J (2007) Quinoline and derivatives at tar oil contaminated site: hydroxylated products as indicator for natural attenuation? Environmental Science \& Technology 47: $5314-5322$

Ringuet J, Leoz-Garziandia E, Budzinski H, Villinave E, Albinet A (2012) Particle size distribution of nitrated and oxygenated polycyclic aromatic hydrocarbons (NPAHs and OPAHs) on traffic and suburban sites of a European megacity : Paris (France). Atmospheric Chemistry and Physics 12:8877-8887

Shen HZ, Huang Y, Wang R, Zhu D, Li W, Shen GF, Wang B, Zhang YY, Chen YC, Lu Y, Chen H, Li TC, Sun K, Li BG, Liu WX, Liu JF, Tao S (2013) Global atmospheric emissions of polycyclic aromatic hydrocarbons from 1960 to 2008 and future predictions. Environmental Science \& Technology 47:6415-6424

Streets DG, Yu C, Bergin MH, Wang XM, Carmichael GR (2006) Modeling study of air pollution due to the manufacture of export goods in China's Pearl River Delta. Environmental Science \& Technology 40:2099-2107

Tsai YI (2005) Atmospheric visibility trends in an urban area in Taiwan 1961-2003. Atmospheric Environment 39:5555-5567

Tsapakis M, Stephanou EG (2005) Occurrence of gaseous and particulate polycyclic aromatic hydrocarbons in the urban atmosphere: study of sources and ambient temperature effect on the gas/particle concentration and distribution. Environmental Pollution 133:147-156 
Vicente ED, Vicente AM, Bandowe BAM, Alves CA (in Press) Particulate phase emission of parent polycyclic aromatic hydrocarbons (PAHs) and their derivatives (alkyl-PAHs, oxygenated-PAHs, azaarenes and nitrated-PAHs) from manually and automatically fired combustion appliances. Air Quality, Atmosphere \& Health. Doi: 10.1007/s11869-015-0364-1

Wakeham SG (1979) Azaarenes in recent lake sediments. Environ Sci Technol 13:1118-1123

Wang G, Kawamura K, Lee S, Ho K, Cao JJ (2006) Molecular, seasonal, and spatial distributions of organic aerosols from fourteen Chinese cities. Environmental Science \& Technology 40:4619-4625

Warzecha L (1993) Separation and analysis of azaarenes from UpperSilesia airborne particulate matter. Chemia Analityczna 38:571-583

Wei YJ, Han IK, Shao M, Hu M, Zhang JF, Tang XY (2009) $\mathrm{PM}_{2.5}$ constituents and oxidative DNA damage in humans. Environmental Science \& Technology 43:4757-4762

Wilhelm M, Matuschek G, Kettrup A (2000) Determination of basic nitrogen-containing polynuclear aromatic hydrocarbons formed during thermal degradation of polymers by high performance liquid chromatography-fluorescence detection. Journal of Chromatography A 878:171-181

Xi'an Municipal Statistics Bureau (2011) Xi'an statistic yearbook. China Statistics Press, Beijing

Xu SS, Liu WX, Tao S (2006) Emission of polycyclic aromatic hydrocarbons in China. Environmental Science \& Technology 40:702708

Yamasaki H, Kuwata K, Miyamoto H (1982) Effects of ambient temperature on aspects of airborne polycyclic aromatic hydrocarbons. Environmental Science \& Technology 16:189-194

You CF, Xu XC (2010) Coal combustion and its pollution control in China. Energy 35:4467-4472

Zhang Y, Tao S, Shen H, Ma J (2009) Inhalation exposure to ambient polycyclic aromatic hydrocarbons and lung cancer risk of Chinese population. Proceedings of the National Academy of Science of the USA 106:21063-21067

Zhou CZ, Zhu XH, Wang Z, Ma XD, Chen JP, Ni YW, Wang W, Mu J, Li XX (2013) Gas-particle partitioning of PAHs in the urban air of Dalian, China: measurements and assessments. Polycyclic Aromatic Compounds 33:31-51 